The first chapter offers an historical perspective, while the second chapter examines the current system for longterm care in the United States. The second section of the book then examines the issues involved in long-term care decisions for case managers. These are referred to as "practice considerations". The emphasis of these chapters is on the complex nature of decision-making in the long-term care setting, and the balancing of such considerations as autonomy, family, and institutional and policy constraints. The third section challenges several traditional concepts in long-term care, such as autonomy, safety and independence, and the ways in which we attach importance to each. The authors in this section offer alternative conceptual frameworks which more adequately capture the practical concerns of the long-term care setting. The fourth section examines the role of the family in making long-term care decisions: what do married couples owe each other; what considerations affect children in making long-term care decisions for elderly parents; how should we address conflicts of interest for family members participating in long-term-care decisions. The final chapter critiques what it describes as the "reactive approach" to ethical conflicts in contemporary bioethics, and argues for a "preventive approach" as more appropriate in the long-term-care setting.

Throughout the book, one is struck by the connections which are made by authors to other work in the book. The reader gets the feeling that the book resembles more a co-authored work (with over a dozen co-authors!) than an anthology. This helps the book maintain a focus and gives the reader a feeling that the book is making progress towards a consistent method for addressing ethical conflicts in a long-term-care setting. This is sorely lacking in many anthologies of this type, which often resemble a collection of very loosely related independent papers.

While the book focuses on ethical decision-making in long-term care, many of the challenges raised to traditional concepts in bioethics can easily be expanded (and indeed, sometimes are) to challenge the adequacy of these concepts, not only for ethical practice in a long-term-care setting, but also for the adequacy of these concepts for practical use in bioethics in general. While this relationship is sometimes addressed, I found myself wishing for an even broader analysis of this. I take this, however, as a positive aspect of the book, as it spurs reflection on the limits and applicability of certain traditional concepts in bioethics, without losing focus on the specific issues at hand.

In general, I believe this to be an outstanding book that will reward careful reading and reflection. As a whole, the book provides a wonderful framework for understanding the complex nature of long-term-care decision-making. I recommend this book highly.

THOMAS MAY
Memorial Medical Center, Springfield,
Illinois, USA

\section{The Older Person: Consent and Care}

Report of the British Medical Association and the Royal College of Nursing, London, British Medical Association, 1995, 63 pages, $£ 6.95$ (BMA/RCN members $£ 5.95)$.

\section{Assessment of Mental Capacity: Guidance for Doctors and Lawyers}

Report of the British Medical Association and The Law Society, London, British Medical Association, 1995, 152 pages, $£ 8.95$ (BMA members $£ 7.95$ ).

Questions about the rights and capacities of a number of disadvantaged groups - young people, older people, people with learning disabilities, people with mental disorders - to manage their affairs and to give or withhold consent to medical treatments have quite rightly been gaining increasing public and professional notice. Discussion in the media has been focused by such high profile cases as that of Tony Bland, for whom a judgment was sought as to the legality of withdrawing his life support system, given his persistent vegetative state. Widespread discussion of such questions is very welcome

For carers and professionals working with these groups of people, decisions about their capacity to determine their affairs and treatment frequently have to be made, even over such day-to-day questions as how far a person with dementia should be required to accept personal care when he or she may not understand or accept the need for it. One of the strengths of The Older Person is that it emphasises the enormously wide range of clinical situations in which ethical decisions about consent need to be made, and shows how the process of seeking a patient's consent must be very flexible in order to maximise the ability of the patient to form an opinion and express it. It is not just a question of asking for permission: the patient has a right to a sustained attempt to explain what is being offered in terms which he or she can understand, and, if necessary, a change to the immediate environment to help the patient to make an appropriate decision. The book shows how good ethical practice and good clinical practice are closely related.

The Older Person focuses "mainly on the ethical problems which arise daily for the minority of older people who require care and treatment, particularly problems related to consent, and our ethical and legal duties as professionals towards these people". A wide range of issues is covered.8 Chapter one describes who "older people" are, pointing out that manyea of their needs are related as much to negative societal attitudes as to needs arising directly out of their age alone. The next four chapters are all concerned with consent. Chapter two considers how to promote patient autonomy and includes a valuable discussion on how to maximise the older person's capacity to make decisions. Chapter three, using the definition of consent given in the code of practice of the Mental Health Act, 1983, describes in practical but general terms how to assess a person's capacity to consent, and goes on to describe the ethical and legal basis of treating people who either cannot or will not give consent. Advance statements, do-not-resuscitate orders, consent to research and legal liability of providers of care are also discussed. Chapter four considers confidentiality and the circumstances under which it may be desirable to disclose information, and chapter five has a short but practical discussion of the principles governing the use of restraints. Chapter six is a concise (six-page) summary of earlier chapters

The great merits of this book are its clarity, accessibility and brevity. It covers, just as it claims, a wide range of ethical issues which arise constantly in the day-to-day care of older people. 
These issues receive clear, practical and useful consideration; principles are set out in a way which allows their extension into less frequently encountered, but difficult ethical dilemmas. The report has the merit of the backing of the BMA and the RCN.

The shortcomings of the book are also a result of its brevity and clarity: it is often dogmatic, setting out principles with little attempt to justify them philosophically or by reference to discussions elsewhere. There are a few (twenty-seven) footnotes, which are well chosen, but left me wanting more, and a useful list of further reading, consisting mainly of earlier BMA, RCN and Law Commission reports, which again left me wanting more direction into the wider medicolegal and ethical literature.

The report was the outcome of a committee's deliberations. This gives it the advantage of balanced and wellinformed views, but at times a rather dry and abstract tone. The author, Henrietta Wallace, has included short case-studies in order to relate the abstract points to clinical situations, and where they are used they are effective, highlighting the way in which ethical issues and good practice are related.

Assessment of Mental Capacity is also a report by a group of informed professionals, in this case lawyers and doctors. Its scope is limited in that, as the title suggests, it concentrates on the assessment of mental capacity. It is not restricted to older people, but only briefly considers the law relating to the capacity of children. It deals only with legal provisions in England and Wales, and mainly with civil law, not criminal law. The Mental Health Act 1983 is not considered, except in passing. These restrictions in scope help to shape the book clearly, and to make it very easy to turn to relevant sections. After useful discussions about confidentiality, the law of evidence and a very practical and imaginative section on how doctors and solicitors can learn to communicate more clearly with each other, the main part of the book tackles legal tests of capacity under nine headings: financial affairs, making a will, making a gift, litigating, entering into a contract, voting, entering into personal relationships, consenting to/refusing medical treatment, and consenting to research and innovative treatment. Each section is very clearly written. Clear definitions and explanations of normal procedures are given, with excellent analyses of the meanings of key expressions such as "understanding the nature of the act and its effect" and "best interest". Important distinctions are made, for example, the fact that a person is a patient of the court of protection (a court empowered to look after the patient's financial affairs) does not of itself mean that the person lacks testamentary capacity. This is an instance of a principle underlying the book, that mental capacity is not a black-andwhite affair, but depends strongly on what decision the patient is being asked to make. The authors make clear what is statute, what is case law and what is in their opinion good practice. There is a wealth of practical guidance: how many readers, for example, would otherwise know how to contact the duty judge out of hours?

This is a clear and immensely valuable book. Its shortcomings are self-imposed by its restricted coverage, or unavoidable because of the uncertainties about how far the recommendations for new legislation published by the Law Commission in March 1995 will be accepted. Its merits are that it is clear and easy to use, and offers in one economical volume a level of understanding of the current law relating to capacity which is hard to find in such accessible form anywhere else.

HUGH SERIES

The Fiennes Centre, Hightown Road, Banbury, Oxfordshire OX16 9BF

\section{Health Information Ethics}

\section{P A Cunniffe, Wellington, New Zealand, Health Information Association of New Zealand, 1995, 93 pages, $\$ 27$.}

The study on which this book is based aimed "to seek to define ethical concerns as they relate to health, to information, to professionalism, and to health information in particular. The purpose is to develop a code of ethics which will address these concerns". There follow chapters on ethics; health, medicine and medical ethics; knowledge, information and knowledge and information ethics; professions and professional ethics; information professionalism; health knowledge and health information, and health information ethics. All this within 86 pages, A4 size and with a potentially useful seven pages of refer- ences at the end. With such a wide field to be covered, each part of which contains several different and challenging issues, brevity and superficiality in most of them is inevitable.

The book sets out to consider whether qualified health information workers should now be recognised as professionals with their own code of ethics. It is suggested that they now have an organised body of knowledge, a recognisable and high level of skill and expertise and have at least some accountability to individual clients and to society for the proper execution of their duties. On this last point, reference is made to the possible growth of malpractice claims against health information providers because of a breach in their duty of care to their clients.

It is not entirely clear, however, just who the health information professional is. On page 44, the author gives as one basis on which professional status for "library and information work" can be sought, the need to "regain the scholar-librarian". Later he considers the educative role of health information and the ethical issues in health education and towardso the end he quotes in full a draft USA Code of Ethics for Health Sciences Librarianship.

In many ways, it might have been more useful to have concentrated on librarianship, especially within medicine and the related sciences and to have considered much more the immediate future impact of newer information technology such as the very wide access to $C D-R O M$ and the World Wide Web, questioning the need for libraries and librarians as we now have them. The effect of this rapidly growing universality of information on all professionals and indeed on society must be a subject of great current concern to any health information association.

The book has several references from New Zealand and may expect a little more knowledge in the reader about what is happening there than in fact exists. The author could have made clearer the rationale behind the selection of the many quotations which are used, as there are some surprising gaps; for example, in considering the "professions and professional ethics" and while generally recognising throughout the position of medicine as an important model of a profession, there is no reference to Starr, nor to the work of Friedson. In a book which reads rather like a mastership thesis, suitably amended for 